\title{
Road safety: challenges and opportunities in Latin America and the Caribbean
}

\author{
Sebastian Martinez ${ }^{1}$, Raul Sanchez ${ }^{2}$ and Patricia Yañez-Pagans ${ }^{2 *}$ (])
}

\section{*Correspondence:}

patriciaya@iadb.org

${ }_{2}^{2}$ IDB Invest, Washington

D.C., USA

Full list of author information is available at the end of the article

\begin{abstract}
An estimated 1.3 million people die in traffic accidents each year worldwide and millions more are injured, with developing countries disproportionately affected. It is predicted that the number of global traffic deaths will be around 1.8 million annually by 2030, making it the eight cause of death in the world. This paper provides an overview of salient road safety issues in the Latin America and Caribbean (LAC) region. It also reviews existing theoretical and causal empirical evidence of interventions to improve road safety outcomes, concentrating on three core areas: safer roads and mobility, safer vehicles, and safer road users. Despite the existence of potentially cost-effective and life-saving interventions, there is surprisingly little rigorous evidence on the effectiveness of road safety programs in the LAC context. This paper discusses promising areas for policy experimentation and future research.
\end{abstract}

Keywords: Road safety, Road traffic accidents, Road fatalities, Latin America and the Caribbean

JEL Classification: R41, R42, L92, 115, K32

\section{Introduction}

Each year, 1.3 million people are killed on roads worldwide, and as many as 50 million are injured (WHO 2015). Approximately, 90\% of deaths and injuries from traffic accidents occur in low- and middle-income countries, where direct and indirect costs are close to US $\$ 65$ billion a year, exceeding the total amount of developmental assistance that these countries receive. ${ }^{1}$ WHO (2015) forecasts that there will be almost 1.8 million traffic fatalities annually by 2030 , and that traffic deaths will be the leading cause of death among those 15-29 years old. According to the Economic Commission for Latin America and the Caribbean (ECLAC 2015), the rate of fatalities from traffic accidents in the region grew from 14.75 to 17.68 deaths per 100,000 population between 2000 and 2010 , an increase of $20 \%$. This fatality rate is almost twice the level observed in highincome countries (10 per 100,000 population) (Diez-Roux et al. 2012).

Traffic deaths and injuries have become a major health and development concern. Research by Wijnen and Stipdonk (2016) shows that social costs of road crashes in highincome countries range from 0.5 to $6 \%$ of GDP, with an average of $2.7 \%$. For low- and

\footnotetext{
${ }^{1}$ According to the Association for Safe International Road Travel. http://asirt.org/initiatives/informing-road-users/road-
} safety-facts/road-crash-statistics (Accessed in May 2018).

(c) The Author(s) 2019. This article is distributed under the terms of the Creative Commons Attribution 4.0 International License (http://creativecommons.org/licenses/by/4.0/), which permits unrestricted use, distribution, and reproduction in any medium, provided you give appropriate credit to the original author(s) and the source, provide a link to the Creative Commons license, and indicate if changes were made. 
middle-income countries, these social costs range from 1.1 to $2.9 \%$, and these values might be underestimated as they do not include the internationally recommended willingness-to-pay method for estimating human costs. A study by the World Bank (2017) estimates both the potential economic benefits and aggregate social welfare gains of reducing road traffic injuries in low- and middle-income countries. The main argument of the authors is that those that are injured in road traffic accidents are disproportionately in their economically productive years, plus there is a substantial burden on limited health system resources. Findings show that, over time, sharply reducing the number of road traffic injuries and deaths would enable these countries to attain substantial increases in economic growth and national income, while leading simultaneously to clear welfare gains.

In 2010, the United Nations (UN) General Assembly proclaimed 2011-2020 as the Decade of Action for Road Safety. In addition, in 2016 the UN General Assembly and its member states adopted a resolution entitled "Improving Global Road Safety" that calls on governments to take a leading role in implementing road safety measures. These measures include adopting comprehensive legislation on key risk factors such as speeding, drinking and driving, and failing to use motorcycle helmets, the use of seatbelts and child restraints, improving the safety of vehicles and roads, and strengthening emergency trauma care for victims of traffic accidents (WHO 2015).

Surprisingly, there is limited causal evidence on the effectiveness of road safety interventions in Latin America and the Caribbean (LAC) or in middle-income and lowerincome countries more broadly. Moreover, the evaluation of road safety programs has traditionally been based on comparisons of outcome variables, such as the number of people injured or killed in traffic accidents before and after a given intervention. As several authors have already highlighted in this literature, the main concern is that these outcomes may be affected by multiple factors (such as drivers' and pedestrians' behavior, road conditions, weather events, and local laws), making it difficult to attribute changes observed over time to a single program or intervention (Elvik 2002; Hauer 1997). Two notable exceptions of rigorous studies conducted in LAC are those by Rau and Otero (2017), who evaluate the impact of drinking laws in Chile, and Blanco et al. (2017), who measure the effects of motorcycle laws in Uruguay.

This paper reviews the challenges and opportunities for addressing road safety in the region using evidence-based solutions. The paper starts by presenting a review of the theoretical literature on the causes of traffic accidents, including perspectives from diverse fields of study including psychology (Froggatt and Smiley 1964; Näätänen and Summala 1974; Fuller and Santos 2002; Summala 1988), transport economics (Elvik et al. 2009), and more recent theories from microeconomics based on utility-maximizing frameworks. This theoretical overview of road safety helps to broaden the understanding of available empirical results and guide the formulation of research questions in future empirical work looking at the causal impacts of road safety interventions.

The paper then examines the available causal evidence on road safety interventions. With a dearth of evidence for LAC, studies that are available for the region are reviewed and a broader overview is provided of the work that has been done in this area worldwide. The review considers interventions within three of the five pillars established by the UN Decade of Action (WHO 2010): (1) safer roads and mobility, (2) safer vehicles, 
and (3) safer road users. The review excludes the road safety management pillar, which has to do with institutional capacity strengthening and data generation, and the postcrash response pillar, which is related more closely to the health and insurance literature, which is outside the scope of this paper.

Overall, the summary of the literature highlights the urgent need to generate evidence for developing countries and especially for LAC. Moving forward, it will be important to strengthen evaluation methods in road safety by giving more careful attention to the definition of the counterfactual situation. The theoretical overview and empirical evidence presented in this paper highlight the multiple trade-offs and complementarities that characterize road safety interventions. This calls for a careful design of impact evaluations in this area, considering the timing of potential effects, crowding-out effects on behavior, and the need to isolate the impact of multiple interventions that may simultaneously affect results.

To construct a solid research agenda with empirical evidence in LAC, first, there is an urgent need to improve information systems in developing countries, as the lack of data is one of the primary constraints to empirical work in this area. For example, in most countries, data on traffic accidents are already being collected, but these data are not yet systematized and can be difficult to access and use. Until more evidence from LAC is generated, literature available from other contexts can be used to help guide road safety intervention design, which may otherwise lack empirical underpinnings due to the absence of context-specific evidence. However, as new road safety interventions are designed, tested, and adapted to the LAC region, it is imperative that these include prospective evaluations that help to strengthen the evidence base on cost-effective ways to achieve safer roads.

\section{Road safety in Latin America and the Caribbean}

Traffic deaths claimed more than 1.4 million lives worldwide in 2013 (Table 1), making them the ninth leading cause of death, just above hypertensive heart disease. Low- and middle-income countries suffered the most, with fatality rates twice as high as those in high-income countries. According to WHO (2015), 90\% of these traffic deaths occurred in low- and middle-income countries. Surprisingly, while these countries represent $82 \%$ of the world's total population, they bear a disproportionate number of deaths, considering that they only hold $54 \%$ of the total number of registered vehicles in the world. By 2030, it is projected that road injuries will be the seventh largest cause of death, above HIV/AIDS, diarrheal diseases, and hypertensive heart disease (see Table 6 in Appendix), and will be the leading cause of death for people aged 15-29 years old (see Table 7 in Appendix).

The risk of death in a traffic accident fluctuates by region, and there has been little change in the trends in national traffic mortality rates since 2010. The highest rates worldwide are in Africa, while Europe is well below the world average (9.3 per 100,000 population), and the global rate is 17.4 per 100,000 population. There is also substantial variation in rates within regions. For example, rates in some of the high-income countries in the Western Pacific region (such as Australia) are among the lowest in the world, while a portion of the region's middle-income countries have rates well above global averages, with 24 deaths per 100,000 population. While high-income countries 


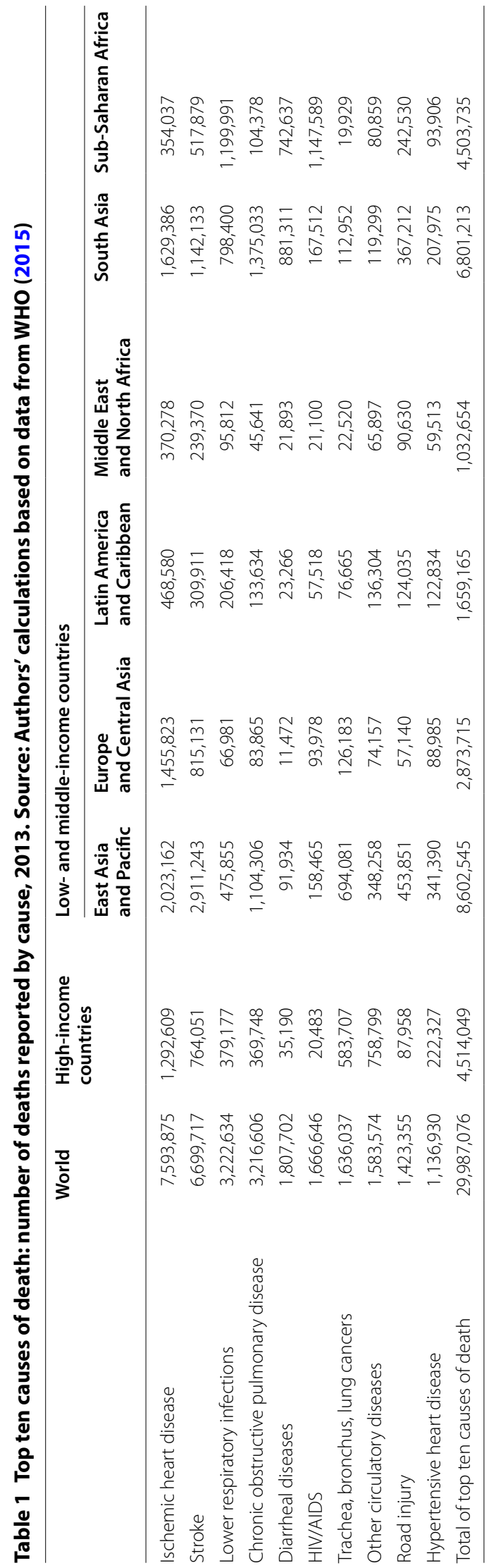


have reduced death rates compared to low- and middle-income countries, high-income nations in the Eastern Mediterranean region have higher rates than their less-affluent neighbors in the region (22.4 compared to 19.7) and more than twofold the regular rate of high-income countries globally (9.2). This evidence suggests that in some of the more affluent Eastern Mediterranean countries, rapid economic development that has resulted in increased motorization and the construction of road infrastructure has not been accompanied by sufficient investment in institutional capacity or by the interventions needed to cope with these changes and ensure that roads are safe.

Almost half of all deaths on the world's roads are of people who have the least protection-motorcyclists, cyclists, and pedestrians. However, the likelihood of dying on the road as a motorcyclist, cyclist, or pedestrian varies by region. Africa has the highest proportion of pedestrian and cyclist deaths, at $43 \%$ of all traffic fatalities, while Southeast Asia presents the lowest rate in the world at 16\%, according to estimates by WHO (2013). The Americas, the Mediterranean, and Europe have moderate rates of 25, 30, and $30 \%$, respectively.

Road traffic injuries place a massive burden on national economies and on households. In low- and middle-income countries, they mainly affect the economically active age group; that is, those persons set to contribute to family, society, and the workforce. Many families are driven deeper into poverty by the loss of a household head, the expenses of extended medical care, or the added burden of caring for a family member who is disabled from a road traffic injury. The economic costs also strike hard at a national level, imposing a significant impact on the health, insurance, and legal systems. This is an important issue particularly for countries struggling with other development needs and where investment in road safety is limited when compared to the scale of the problem. Data suggest that traffic deaths and injuries in low- and middle-income countries cause economic losses of up to 5\% of Gross Domestic Product (GDP) among these countries (WHO 2015). Globally, an estimated 3\% of GDP is lost to traffic deaths and injuries (WHO 2018).

It is estimated that there were 124,035 traffic deaths in LAC in 2103, with an average death rate of 17.55 per 100,000 population. Similar to the patterns observed worldwide, estimated mortality rates due to road traffic injuries also vary among sub-regions and countries, with death rates ranging from 16.46 per 100,000 population in the Southern Cone sub-region to 18.27 in the Mesoamerica sub-region (Fig. 1). ${ }^{2}$

Table 2 shows that deaths of drivers and/or passengers in four-wheel vehicles account for most of the traffic deaths in many countries, with percentages that range from $2.5 \%$ in Peru to $60.8 \%$ in Bolivia. The highest proportion of deaths among riders of two- and three-wheel vehicles occurs in Colombia and the Dominican Republic, at 52.5 and $67.0 \%$, respectively, of total traffic deaths. Finally, $30 \%$ of traffic deaths in LAC are pedestrians and cyclists, with the highest shares corresponding to Dominica (60.0\%).

Wearing a seatbelt reduces the risk of a fatality among drivers and front-seat occupants by $45-50 \%$ and the risk of minor and serious injuries by 20 and $45 \%$, respectively

\footnotetext{
2 The sub-regions in Latin America and the Caribbean are the following: the Latin Caribbean (Cuba and Dominican Republic), the non-Latin Caribbean (The Bahamas, Barbados, Dominica, Guyana, Jamaica, St. Kitts and Nevis, St. Lucia, St. Vincent and the Grenadines, Suriname, and Trinidad and Tobago), the Southern Cone (Argentina, Brazil, Chile, Paraguay, and Uruguay), Mesoamerica (Belize, Costa Rica, El Salvador, Guatemala, Honduras, Mexico, Nicaragua, and Panama), and the Andean South region (Bolivia, Colombia, Ecuador, Peru, and Venezuela).
} 


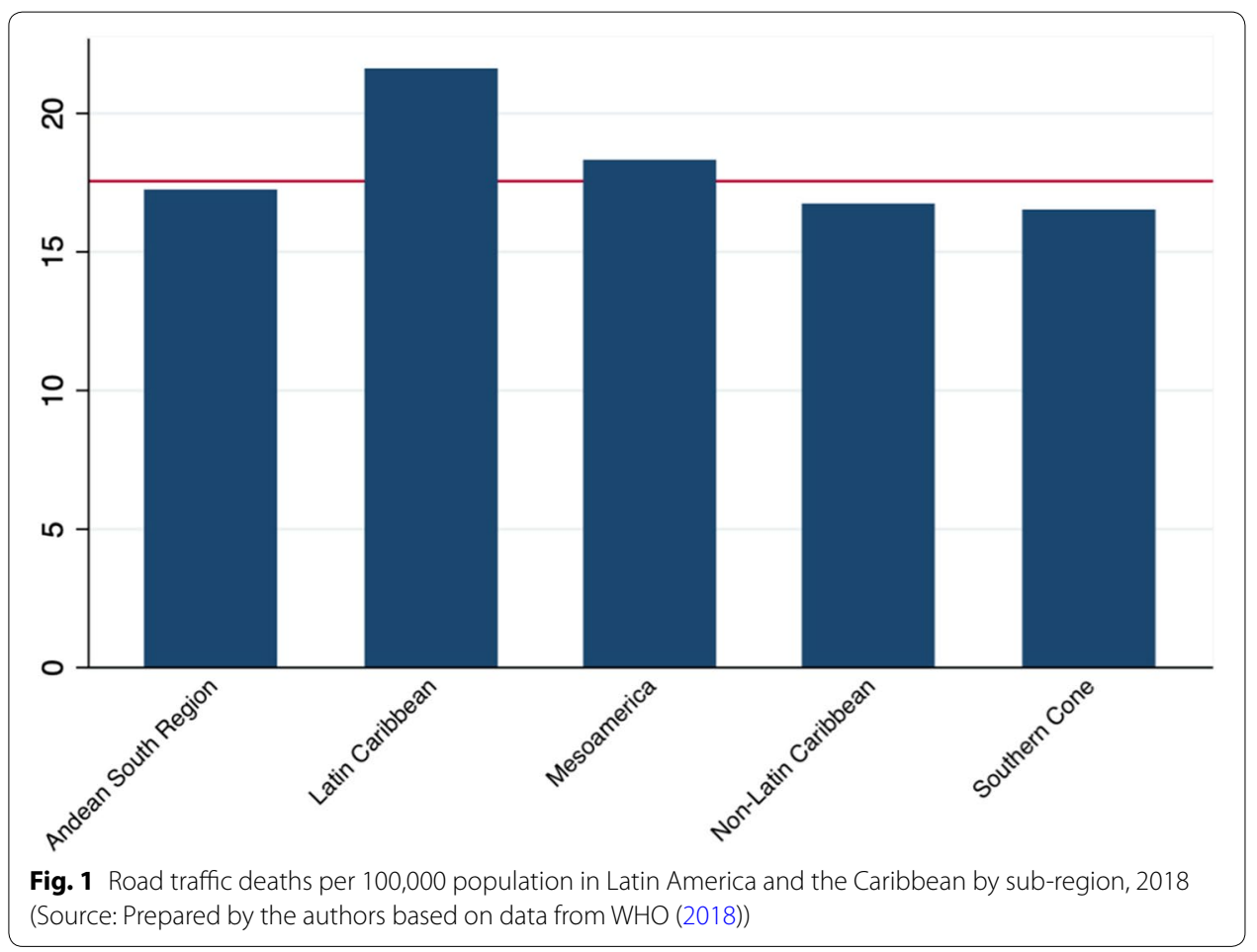

(Elvik et al. 2009). Table 3 presents estimates of the proportion of car occupants (i.e., drivers and passengers) who use seatbelts, highlighting high variability across countries. For instance, only $39 \%$ of front-seat passengers wear a seatbelt in the Andean South subregion, compared to an $85 \%$ of passengers in the Latin Caribbean sub-region.

Several countries have achieved sustained reductions in traffic-related injuries and fatalities through effective road safety programs that included legislative change (Peden et al. 2004; WHO 2013). According to data collected by WHO (2018), all LAC countries have national legislation requiring the use of helmets on motorcycles and/or mopeds. Despite this, there is wide variation within sub-regions in the application of this type of legislation. For example, while all countries in the Southern Cone require helmets to meet certain (national or international) standards, only 14 and $60 \%$ of the countries in Mesoamerica and the Andean South, respectively, have this requirement (see Table 8 in Appendix).

In terms of alcohol consumption and driving, while all countries in the region have drunk driving laws, not all of them have a clear definition of what should be considered a violation based on blood alcohol content. The most recent data indicate that most of the countries in LAC (except in Mesoamerica, with 78\%) have a drunken driving definition based on blood alcohol limits (Table 4).

Ensuring that vehicle manufacturers build in seatbelts and the necessary features for child restraints are critical for reducing road traffic fatalities. Ten of thirty-three LAC countries have standards for front and rear seatbelts on new cars manufactured or assembled in the country, and twenty-three have standards for new imported cars.

Vehicle safety standards and regulations are uneven among LAC countries (Table 5). Most of the countries in the Southern Cone and Andean regions have 
Table 2 Distribution of traffic deaths by type of road user (percent). Source: Prepared by the authors based on data from WHO (2018)

\begin{tabular}{|c|c|c|c|c|c|}
\hline Country & $\begin{array}{l}\text { Drivers/passengers } \\
\text { in four-wheel } \\
\text { vehicles }\end{array}$ & $\begin{array}{l}\text { Drivers/passengers } \\
\text { in motorized two- } \\
\text { or three-wheel } \\
\text { vehicles }\end{array}$ & Cyclists & Pedestrians & $\begin{array}{l}\text { Other/ } \\
\text { unspecified } \\
\text { road users }\end{array}$ \\
\hline Argentina & 47.2 & 22.2 & 2.4 & 8.2 & 20.0 \\
\hline Bahamas $^{a}$ & 57.7 & 17.3 & 3.8 & 21.2 & - \\
\hline Barbados & 33.3 & 33.3 & 0.0 & 22.2 & 11.1 \\
\hline Belize & 18.8 & 19.8 & 11.9 & 24.8 & 24.8 \\
\hline Bolivia & 60.8 & 19.7 & & 2.5 & 17.1 \\
\hline Brazil & 23.2 & 31.4 & 3.4 & 18.1 & 24.0 \\
\hline Chile & 42.0 & 8.7 & 5.7 & 36.0 & 7.7 \\
\hline Colombia & 8.4 & 52.5 & 5.3 & 26.0 & 7.8 \\
\hline Costa Rica & 24.0 & 40.0 & 10.4 & 24.7 & 0.9 \\
\hline Cuba & 10.1 & 15.6 & 9.9 & 33.2 & 31.2 \\
\hline Dominica & 10.0 & 0.0 & 60.0 & 10.0 & 20.0 \\
\hline Dominican Republic & 11.0 & 67.0 & 1.0 & 17.0 & 4.0 \\
\hline Ecuador & 5.2 & 19.1 & 1.8 & 19.8 & 54.0 \\
\hline El Salvador & 32.1 & 14.2 & 1.4 & 49.0 & 3.3 \\
\hline Guatemala & 19.4 & 32.7 & 0.4 & 39.2 & 8.3 \\
\hline Guyana & 24.2 & 21.9 & 12.5 & 29.7 & 11.7 \\
\hline Honduras & 18.6 & 24.3 & 4.1 & 27.9 & 25.1 \\
\hline Jamaica & 33.0 & 28.8 & 8.4 & 22.2 & 7.7 \\
\hline Mexico & 18.4 & 9.6 & 1.1 & 28.5 & 42.4 \\
\hline Nicaragua $^{a}$ & 23.2 & 26.0 & 5.5 & 32.8 & 12.5 \\
\hline Panama & 32.3 & 4.4 & 5.7 & 40.0 & 17.5 \\
\hline Paraguay & 16.5 & 52.2 & 0.2 & 22.5 & 8.7 \\
\hline Peru & 2.5 & 0.6 & 0.2 & 8.1 & 88.6 \\
\hline Saint Lucia & 46.7 & 20.0 & 13.3 & 13.3 & 6.7 \\
\hline Suriname & 33.8 & 45.9 & 4.1 & 14.9 & 1.4 \\
\hline Trinidad and Tobago & 57.8 & 2.2 & 0.7 & 31.1 & 8.1 \\
\hline Uruguay & 30.7 & 45.7 & 7.0 & 16.6 & 0.0 \\
\hline Region average & 27.4 & 25.0 & 6.9 & 23.7 & 17.9 \\
\hline
\end{tabular}

a WHO (2015)

Table 3 Seatbelt wearing rate (percent). Source: Prepared by the authors based on available data from WHO (2015)

\begin{tabular}{llcll}
\hline Sub-regions & Front seat & Rear seat & Drivers only & All occupants \\
\hline Andean South & 38.60 & 3.40 & 79.85 & 55.60 \\
Latin Caribbean & 85.00 & 10.00 & 90.00 & 60.00 \\
Mesoamerica & 63.15 & 25.20 & 69.63 & 70.00 \\
Non-Latin Caribbean & 76.33 & 4.00 & 75.33 & - \\
Southern Cone & 61.88 & 34.76 & 64.10 & 47.15 \\
\hline
\end{tabular}

Numbers reported are the average of rates observed in countries within each sub-region

national policies that promote investment in or use of public transportation. Similarly, most countries have national policies that promote non-motorized modes of transportation, such as walking and cycling. Furthermore, all countries in these two 
Table 4 Definition of drunk driving by blood alcohol content, by region (percent). Source: Prepared by the authors based on data from WHO (2018)

\begin{tabular}{lll}
\hline Sub-regions & $\begin{array}{l}\text { Definition of drunk driving by blood } \\
\text { alcohol content }\end{array}$ & $\begin{array}{l}\text { Existence } \\
\text { of a national drunk } \\
\text { driving law }\end{array}$ \\
\hline Andean South & 100 & 100 \\
Latin Caribbean & 100 & 100 \\
Mesoamerica & 78 & 100 \\
Non-Latin Caribbean & 100 & 100 \\
Southern Cone & 100 & 100 \\
\hline
\end{tabular}

Table 5 Percentage of countries with different types of vehicle safety standards and regulations. Source: Prepared by the authors based on data WHO (2018)

\begin{tabular}{lcccc}
\hline Sub-regions & $\begin{array}{l}\text { National policy } \\
\text { on public transport }\end{array}$ & $\begin{array}{l}\text { National policy } \\
\text { on walking } \\
\text { and cycling }\end{array}$ & $\begin{array}{l}\text { Road safety } \\
\text { lead agency }\end{array}$ & $\begin{array}{l}\text { National road } \\
\text { safety strategy }\end{array}$ \\
\hline Andean South & 100.00 & 75.00 & 100.00 & 100.00 \\
Latin Caribbean & 100.00 & 50.00 & 100.00 & 100.00 \\
Mesoamerica & 80.00 & 80.00 & 100.00 & 100.00 \\
Non-Latin Caribbean & 60.00 & 23.00 & 88.89 & 55.56 \\
Southern Cone & 100.00 & 100.00 & 100.00 & 100.00 \\
\hline
\end{tabular}

sub-regions have a government agency responsible for coordinating road safety. However, regionally, $50 \%$ of countries still need a national strategy on road safety to set out the main principles, to define goals and objectives, to prioritize actions, and to coordinate mechanisms for preventing road traffic injuries and reducing their consequences.

\section{Theoretical framework}

Road safety policies have been analyzed using the tools of enforcement, education, and engineering, and from the standpoint of traffic engineers, economists, psychologists, statisticians, public health professionals, and urban planners. Thus, establishing a unique conceptual framework for road safety is not an easy task. For instance, while economists tend to analyze optimal driving decisions, engineers examine the physical characteristics of roads and cars. This section reviews the main theoretical frameworks that have guided studies in this field and that ultimately seek to understand and explain the main causes of traffic accidents.

\subsection{Theories based on human factor aspects and systems}

The first theory that studied the causes of road accidents can be categorized as an accident proneness theory, where the human factor is the main explanatory variable. Developed by psychological researchers in 1926 (Froggatt and Smiley 1964), the theory considers that certain individuals are more likely than others to be involved in traffic accidents, even though there are no differences in risk exposure (Farmer and Chambers 1940). Tillmann and Hobbs (1949) examined many lifestyle variables that might affect driving and concluded that high-accident taxi drivers most frequently 
come from a home marked by parental divorce and instability. The main critique to this theory was the small statistical evidence to prove these arguments.

Other theoretical studies concentrated on the human factors contributing to traffic accidents. Some studies attributed accidents to a chain of events ultimately caused by human error (Reason 1990). These errors were broadly categorized as overload (the task is beyond the capability of the driver, either by physical, psychological, or by environmental factors), inappropriate driver response (either the driver's or the authority's fault), and inappropriate activities (for instance, a lack of training).

More recent studies introduce a different theoretical approach by proposing a system theory where traffic accidents occur because of a failure of the whole traffic system (interaction between the driver, vehicle, and road infrastructure) rather than only a failure of the driver as postulated by previous theories (Elvik et al. 2009). The main argument behind this theory is that the demand for mobility puts the driver in a complex system where he or she has limited capacity. Therefore, this theory contemplates that the systems should be designed to reduce complexity, thereby helping to prevent errors from occurring.

\subsection{Cognitive/psychological theories}

The system theory treats the driver as a passive responder in his or her environment. However, the evidence shows that the driver is in fact an active participant and regulates his or her level of preferred risk. For this reason, several psychological models were developed to explain what determines the driver's speed choice. Theories in this area focus on the driver's behavior and motivations for achieving a certain outcome given a particular risk level (Fuller 2005).

Following work in psychology (Taylor 1964), Näätänen and Summala (1974) developed the first psychological approach to road safety. The authors suggested the idea of zerorisk theory, which states that the primary motive for using a specific means of transport is the mobility provided by the vehicle. Then, the risk which the driver perceives in a situation corresponds to the perceived likelihood of a hazardous event. As experience increases, self-confidence increases as well, and the perceived risk diminishes to the point of zero perceived risk. Therefore, experienced drivers feel that there is no real risk at all.

Wilde (1982) formulated the risk homeostasis theory, ${ }^{3}$ which states that for any activity, people accept a level of associated risk and safety, referred as the "target level of risk." If people perceive that the degree of risk is low and acceptable, then they modify their behavior to increase their exposure to risk. Conversely, if they see a higher than acceptable level of risk, they will compensate by exercising greater caution. Therefore, people do not always respond as expected to traditional safety initiatives, but rather adjust their response to more rules, administrative controls, new procedures, and engineering technologies according to their target level of risk. Fuller and Santos (2002) proposed the idea of task difficulty homeostasis: drivers seek to maintain a given level of task difficulty.

\footnotetext{
${ }^{3}$ Homeostasis refers to the tendency toward a relatively stable equilibrium between independent elements, especially as maintained by physiological processes. For a discussion on the strengths and weaknesses of this theoretical approach, see Wilde et al. (2002)
} 
Speed is proposed to be the primary mechanism whereby drivers regulate the difficulty of the task. However, speed choice is also determined by other motivations, such as time constraints. A key component of this theory is that different drivers have different capabilities, and that they balance the difficulty of a given task with their ability to safely complete the task.

In some situations, people's reaction to a policy might reduce the expected outcomes. Suppose that engineers can demonstrate that, under certain circumstances, airbags reduce the risk of injury in a car accident by $25 \%$. Whether or not the application of these devices reduces the fatality rate by $25 \%$ depends on the response of drivers to the increased protection from dangerous accidents. If drivers increase their driving intensity (speed, recklessness, and driving while intoxicated), because they feel like they are more protected by the airbags, then actual fatalities avoided may be lower than the $25 \%$ predicted. Crandall and Graham (1984) describe this situation with the concept of offsetting behavior. The authors explain that such behavior is not irrational; it merely represents a substitution of the marginal benefits of driving intensity for the reduced marginal cost of risk. This theory was extended by the risk-compensation theory, where users respond to or compensate for perceived changes in the dangers to which they are exposed (Elvik et al. 2009). Therefore, measures designed to improve traffic safety may provoke negative consequences from increased riskiness of driving behavior, because individuals feel safer (Dulisse 1997).

Elvik (2004) considers that the risk homeostasis and risk-compensation theories are too vague in explaining the specific underlying behavioral mechanisms, which makes empirical testing extremely difficult. According to the author, the behavioral adaptation is a wider term referring to all behavioral changes triggered by a safety measure. After changes in the road-vehicle system are implemented, road users sometimes adapt their behavior in a manner inconsistent with the initial goals of the safety measures: for instance, safer highways and safer cars often lead to more dangerous driving habits.

\subsection{Economic theories of road safety}

The psychology-based models presented above help to provide further understanding of drivers' mental processes and behavior, while the economic-based models of individual driver behavior presented in this subsection assume rational behavior (which is usually taken to represent the aggregate behavior of the driving population). When compared to psychological approaches, one benefit of economic approaches is that they are more tractable and it is easier to develop hypothesis tests for them (Michon 1989).

The first analysis of road safety within the economic literature corresponds to Peltzman (1975), with an application of the risk-compensation theory. The author focused on United States regulatory measures implemented in the mid-1960s to improve vehicle safety. He challenged the effectiveness of these policies by estimating a model that assumes that drivers are rational agents who choose between safety and driving intensity. Line A in Fig. 2 represents the trade-off between the probability of an accident and driving intensity. As can be seen, more driving intensity is associated with forgoing some safety. When safety devices are available or mandated, the price of driving intensity declines (resulting in a turnover of the trade-off rate to line $\mathrm{B}$ ). The distance between points $C$ and $D$ represents the magnitude of the effect of the devices. The 


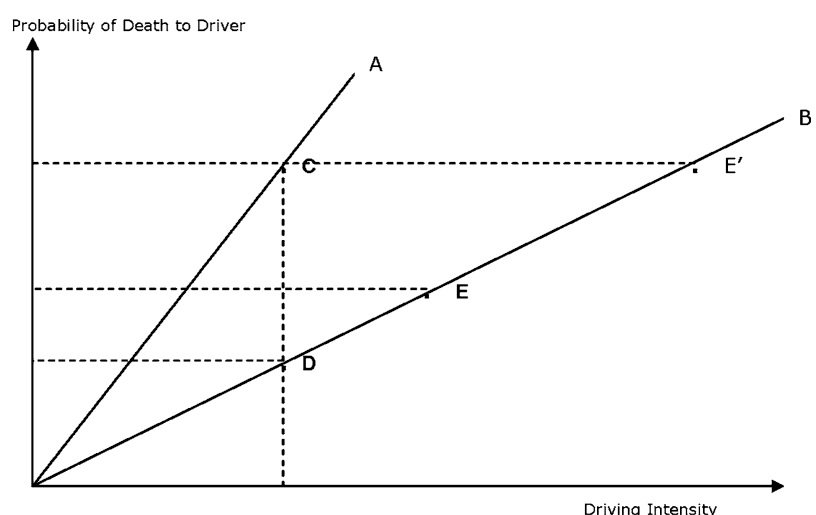

Fig. 2 Risk compensation (Source: Peltzman (1975))

author states that if one treats driving intensity as a normal good, the consumption equilibrium lies in point $\mathrm{E}$ instead of $\mathrm{D}$. He claims that lowering the cost of driving intensity will lead to an increase of consumption and thereby enlarge the safety risk.

To test this theory, the author analyzes the determinants of the accident rates for the period before the federal regulation is implemented and uses these estimates to project, for the following period, the rates that could have occurred without the policy. The effects of regulation are then obtained by comparing the expected rates with actual rates. The author estimates the following reduced form:

$$
R=f(P, Y, T, A, S, K, u),
$$

where $R$ is the adjusted total death rate (per vehicle mile); $P$ is the cost component of an accident based on physician and hospital costs, and insurance premiums; $Y$ is the real labor income per working-age adult; $T$ is the time trend; $A$ is the amount of alcoholic intoxication among the population at risk (measured by per capita consumption of distilled spirits); $S$ is the average speed of motor vehicles on non-interstate rural roads at off-peak hours; $K$ is the ratio of the 15-25 year old population to the rest of the driverage population; and $u$ represents random factors. The expected derivatives are the following: $\frac{\partial R}{\partial P}\left\langle 0, \frac{\partial R}{\partial Y}(?), \frac{\partial R}{\partial P}\left\langle 0, \frac{\partial R}{\partial A}\right\rangle 0, \frac{\partial R}{\partial S}\right\rangle 0$, and $\frac{\partial R}{\partial K}>0$.

The first utility-based framework of the risk-compensation theory corresponds to O'Neill (1977). According to the author, a safety improvement is one that would reduce accidents given fixed driver behavior. However, drivers may respond to it by driving less carefully than before, thus diverting the improvement toward some nonsafety goal such as quicker arrival at a destination. In this model, the driver's only motivation is to arrive at his or her destination, and the driver's only range of choices is the selection of speed $(v)$. Let $U_{\mathrm{T}}$ be the utility per hour of traveling without accidents, $U_{\mathrm{A}}$ the utility of having an accident, and $p$ the accident rate per mile. For simplicity, it is assumed that $U_{\mathrm{T}}$ and $U_{\mathrm{A}}$ are independent of $v$ and $p$. It is assumed that there is a one-to-one relationship between these two variables: the faster the driver goes, the more likely he or she is to have an accident. Therefore, choosing $v$ and choosing $p$ are equivalent. The driver will then choose the value of $p$ that maximizes the following expected utility function: 


$$
E U(p) \equiv \frac{U_{T}}{v(p)}+p U_{A}
$$

In an extension of this model, the authors include a parameter $\sigma$ that represents changes in the driving environment, such as infrastructure conditions, and then, $v$ is expressed as $v(p, \sigma)$. A low $\sigma$ represents a low degree of safety and causes higher $p$ to be associated with a given speed $\nu$. If the safety parameter $\sigma$ is shifted, the driver will be led to choose a new $p$ to maintain the previous condition. A detailed analysis of this model reveals that the direction of change of the accident rate depends on the shape of the functions relating speed and the accident rate before and after the safety change, but not on the driver's utilities for speed or accidents. Therefore, all rational drivers should increase their accident rate in response, or all should decrease it. There is no possibility of a mixed reaction in which some drivers increase their accident rate and others decrease it, depending on their utilities.

Janssen and Tenkink (1988) proposed a modified version of the previous model to analyze how individuals trade off risk versus travel time. Following the previous formulation, let $L$ be the length of the trip in units of distance. The driver will choose $v$, such that:

$$
U_{\mathrm{L}}=U_{\mathrm{T}} \cdot \frac{L}{v}+L \cdot p \cdot U_{\mathrm{A}}
$$

where the first term represents the driver's expected loss by undertaking a trip lasting $L / v$ hours. The second term is the expected accident loss on the trip. Depending on the exact nature of the relationship between speed and its consequences in terms of accidents, the driver's response will achieve risk homeostasis, meaning that individuals tend to stay at a relatively stable equilibrium in terms of the level of risk that they are willing to take.

As discussed, risk compensation is a natural part of human behavior when individuals pursue multiple goals with limited resources. Following this principle, Blomquist (1986) proposed an economic model that involves utility maximization of traffic safety behavior, based on drivers having useful information to make rational decisions. As in the previous models, $p$, the probability that a motorist is involved in an accident is influenced by the driver's own safety effort $(e)$ and exogenous safety measures $(s)$ that are beyond the driver's immediate control. Let $p(e, s)$ be the production function with $p_{e}<0, p_{e e}>0, p_{s}<0, p_{s s}>0$, and $p_{e s}>0$. The loss $L$ which a driver suffers, given that an accident occurs, depends on the driver's own safety effort and exogenous safety factors: $L(e, s)$, with $L_{e}<0, L_{e e}>0, L_{s}<0, L_{s s}>0$, and $L_{e s}>0$. Finally, there is a disutility $D$ associated with the driver's safety effort and exogenous safety factors, such that $D(e, s)$, with $D_{e}>0, D_{e e}>0, D_{s} \geq 0, D_{s s} \geq 0$, and $D_{e s} \geq 0$. This element can represent a driver's inconvenience, discomfort, energy, or money. If the motorist has a resource constraint represented by income $(I)$ and is risk-neutral, then the expected utility is:

$$
U=p(e, s)[I-D(e, s)-L(e, s)]+[1-p(e, s)][I-D(e, s)] .
$$

The optimal level of the driver's safety effort is determined by $\frac{\partial U}{\partial e}=0$, or $-D_{e}=p_{e} L+p L_{e}$, the point at which the marginal value of the driver's utility cost equals 
the marginal benefit of the expected reduction loss. This result also indicates that in general, motorists will change their behavior $(e)$ in response to a change in exogenous safety $(s)$. By applying the implicit function, it can be demonstrated that

$$
\frac{\mathrm{d} e}{\mathrm{~d} s}=-\frac{-p_{e s} L-p_{e} L_{s}-p_{s} L_{e}-p L_{e s}}{-D_{e e}-p_{e e} L-2 p_{e} L_{e}-p L_{e e}}<0 .
$$

The negative sign of this expression implies that an increase in exogenous safety will induce drivers to adjust their safety behaviors considering risk compensation.

As has been shown before, utility maximization theories include risk as one of the possible driver choices. However, there are no precise formulations of what motivates the drivers to choose a certain level of risk. Rothengatter (1988) argues that it is not just risk (or its avoidance) that motivates drivers to select their speed, but that there may be other factors, such as the pleasure of driving fast, which calls for a broader utility framework. The demand for transportation is a derived demand motivated by the desire to access various activities. And while there is a motivation to reduce travel time, other attributes should also be considered in the analysis.

Another study that presents a suitable micro-founded formulation of driving behavior that applies the concept of risk compensation is that of Dulisse (1997). Figure 3 presents the theoretical foundation of his choice model. Suppose that an individual has to decide between two goods: safety $(S)$ and some other good $(O$, which could represent driving speed, and thus less travel time). Curve 1 represents the combinations of $S$ and $O$ that yield equal satisfaction to the driver. The point at which the budget constraint (represented by the straight line A) is tangent to the preferences generates optimal satisfaction. At point A, the individual consumes $S_{1}$ amount of safety and $O_{1}$ amount of some other good. Assume that because of a safety intervention, keeping all else constant, the individual receives an increase in the amount of safety without reducing the amount of other goods he or she possesses (point B). This process implies a parallel upward shift of the budget constraint. However, the combination of safety $\left(S_{2}>S_{1}\right)$ and the other good $O_{1}$

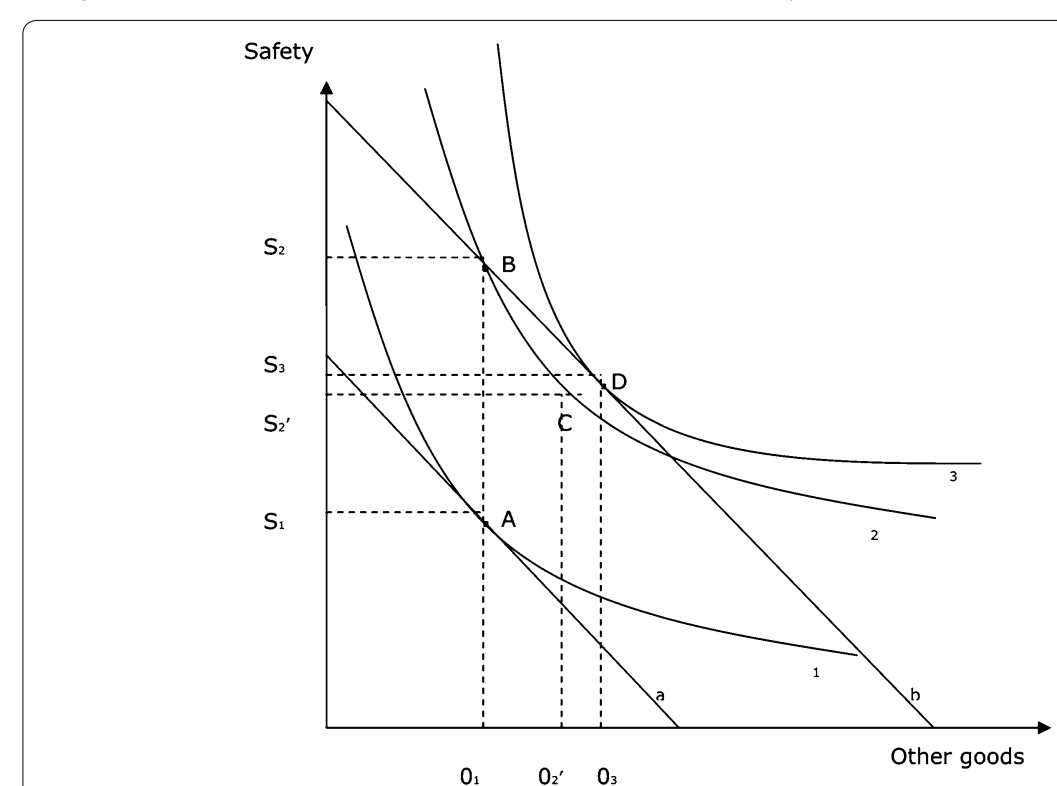

Fig. 3 Choice theory between safety and other goods (Source: Dulisse (1997)) 
is not an optimal decision according to the individual's indifference mapping. By trading away enough safety in exchange for the other good, the driver reaches point $\mathrm{D}$, where satisfaction is optimal given the trade-off rate. According to the author, the hypothesis of risk compensation does not imply that drivers expose themselves to more risk because of the safety intervention. It implies that they will choose actions that are riskier than the action previously chosen (from $S_{2}$ to $S_{3}$ ). Even with the riskier actions, it is likely that the individual will have more safety than before the intervention $\left(S_{3}>S_{1}\right)$.

In a more recent article, Noland (2013) presents a theoretical framework that unifies many of the previous theories to explain the driver's offsetting actions as a result of increases in mobility. This idea fits within the framework of utility maximization originally proposed by Blomquist (1986), in which drivers make trade-offs between mobility and safety. If one assumes that individuals decide upon explicit trade-offs between risk and mobility, Fig. 4 illustrates the isoquant for a given level of technology. The technology can be safety devices available for vehicles and the existing road infrastructure. Movements along with a given isoquant represent the trade-off that an individual makes in selecting a given bundle of safety and mobility.

Any exogenous technological change can have an impact on both mobility and safety, and is represented by a parallel isoquant to the right of the original one. If the initial levels of mobility and safety are set at point $\mathrm{A}$ in the figure, the new levels after a new technology is introduced will depend on the shape of the driver's preference curves. Point $B$ represents the engineering hypothesis, where all the benefits are associated with reductions in risk (more safety), with no offsetting behavioral reaction. Point $\mathrm{D}$ shows a case where risk might even increase due to large increases in mobility. Point $C$ is the most likely outcome, where some of the benefits of the new technology reduce risk, while some increase mobility.

Transport economics views travel demand as a function of the time and price of travel. Consumers can also purchase more safety technologies such as vehicles fully equipped with air bags; thus, there is an additional trade-off between costs and risk. For those choosing to drive a car, the choice of speed provides an explicit trade-off between time and risk, if drivers accurately perceive either of these factors. Elvik (2010) argues that drivers' choice of speed is not objectively rationale. This is largely based on the misperceptions which drivers have about the relative risk of higher speeds and their

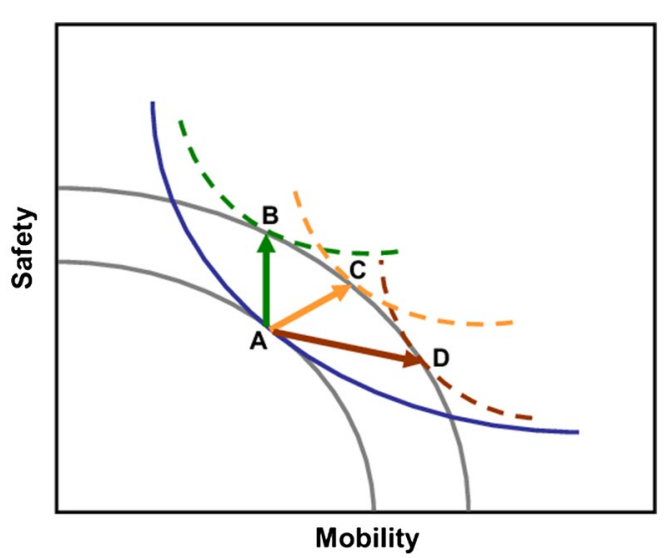

Fig. 4 Trade-offs between safety and mobility (Source: Noland (2013)) 
misperception of the travel time savings associated with higher speeds. Driver distraction and fatigue may also play a role in the risk of driving. A relevant question is whether roads and vehicles perceived to be safer may influence the likelihood of drivers engaging in distracting behavior or not taking care if they are fatigued. For instance, cell phone usage is one activity that clearly has benefits to drivers, but that increases risk.

Within this context, Noland (2013) specifies the utility of travel $(U)$ as a function of price $(P)$, travel time $(T)$, in-vehicle activities ( $A$, such as those that lead to distractions), capability $(C)$, and risk $(R)$, such that:

$$
U=f(P, T, A, C, R) .
$$

Consumers then seek to maximize utility within their constraints and the given technologies. The utility of travel may also be affected by other factors, such as the reliability of the journey, the convenience of intermodal exchanges, and the comfort of alternative modes. These factors can easily be included in a general framework and might even have implications for risk-taking. For example, if traffic time is unpredictable due to congestion, this may lead to various risk-taking activities to minimize travel time. Increased comfort may cause travelers to misperceive their capability levels, which can affect attention levels, with consequent trade-offs with risk.

The specific functional form will determine how a change in risk affects a change in other attributes, that is, the elasticity of substitution. Maximization of utility represents the motivation of the driver, which is typically to increase mobility. A key controlling factor is a trade-off with travel time, which is controlled by the choices of the individual.

As described in this section, theoretical frameworks on road safety have evolved over time in multiple disciplines of study, providing different explanations as to the main causes of traffic accidents. However, as discussed in the next section, the empirical evidence that puts these theories and predictions to the test remains limited, particularly for the LAC context.

\section{Road safety interventions}

This section reviews the causal evidence on the effectiveness of road safety interventions. It highlights the studies that have been done in LAC countries, but, given the limited evidence in the region, also provides a broader overview of the literature from which valuable lessons can be extracted to advance research in this area in LAC. The review is structured considering interventions within three of the five pillars established by the UN Decade of Action (WHO 2010): (1) safer roads and mobility, (2) safer vehicles, and (3) safer road users. The pillars excluded are the road safety management, which has to do with institutional capacity strengthening and data generation, and the post-crash response, as this is related to health and insurance interventions that are outside the scope of this work.

\subsection{Promoting safer road users}

\subsubsection{Road safety education programs for pedestrians}

Education measures to teach pedestrians how to cope with the traffic environment are frequently included in road safety strategies. Among high-risk populations, children between 6 and 10 years old are estimated to have four times the risk of collision 
compared to adult pedestrians (Struik et al. 1988; Thomson 2005). The unintentional injury of children is a significant public health problem worldwide and an important financial burden for society (Schwebel et al. 2014a, b). In the United States, more than 3000 children aged 1-14 years old die annually from unintentional injuries and more than 6 million hospital visits are recorded. In Latin America, the total number of deaths for children in the same age range was 6642 in 2013 (2015). In 2005, the total cost of medical expenses for U.S. children aged 1-14 who were hospitalized following unintentional injury was more than US\$15 billion (National Center for Injury Prevention and Control 2013). For Latin American countries, Bhalla et al. (2013) estimate that the total cost of road injuries for children aged 1-14 was between US $\$ 500$ million and US $\$ 1.5$ billion in 2011.

As Schwebel et al. (2014a) indicate, crossing streets safely is a complex process that requires multiple steps: choosing an appropriate location, judging the speed of oncoming traffic, and crossing the street in a suitable manner. Taking this into account, while education is considered an essential tool to teach children road safety skills, current programs may be limited, because they may not target specific skills or may not be tailored for those who are most in need of training (Congiu et al. 2007). Within the set of policy options and programs to respond to this issue, many countries (particularly highincome countries) have implemented road safety education programs directed at both parents and children. Accident and pedestrian observation studies indicate that in many instances, parents do not provide adequate supervision and control for very young children in traffic (Downing et al. 1981). Programs have evolved over time from classroom training to multimedia and virtual reality training.

Due to the nature of education programs, where treatment is usually assigned at the individual level, this is an area of study that has great potential for evaluation using randomized-controlled trials. Nevertheless, many studies identified in the literature suffer from multiple methodological limitations. Duperrex et al. (2002) conduct a systematic review of randomized-controlled trials of road safety education programs for pedestrians of all ages. As the authors highlight, most studies identified did not comply with adequate randomized allocation procedure ${ }^{4}$ and lost participants at follow-up. In addition, in some cases, the outcomes were known by participants, which could have biased their behavior. Multiple studies relied on small sample sizes, that compromise the balance between treatment and control groups and limit statistical power. Also, a few studies discuss or statistically test the similarities between treatment and control groups after randomization. The authors conclude that pedestrian safety education programs seem to change road-crossing behavior, but whether this reduces the risk of pedestrian injury in road traffic crashes is still unknown. They also highlight the lack of evidence coming from safety education programs that target adult pedestrians, especially elderly people, as well as the lack of evidence for low- or middle-income countries.

More recently, Schwebel et al. (2014b) updated the systematic review of studies that evaluate pedestrian safety education programs for children. The authors incorporate meta-analysis techniques and discuss the effectiveness of different types of behavioral interventions, considering five categories: individualized or small-group training,

4 The Cochrane method followed by this study involves both the rigorous generation of a random assignment process as well as its strict implementation (http://methods.cochrane.org/bias/assessing-risk-bias-included-studies). 
classroom training, computer-based or virtual reality training, board games or peergroup activities, and film or video training. Similar to Duperrex et al. (2002), none of the studies identified by the authors comes from a developing-country context. The authors find that behavioral interventions improve children's pedestrian safety, both immediately after training and at follow-up several months later. Available evidence suggests that interventions targeting dash-out prevention, crossing at parked cars, and selecting safe routes across intersections were the most effective, as was individualized/small-group training. The authors also find poor methodological quality in many studies and argue that additional rigorous research is necessary. To assess quality, they consider the following aspects: (1) selection bias, related to poor randomization processes; (2) detection bias, related to the fact that study populations are aware of the experiment and of the outcomes being tested; (3) attrition bias or loss of sample over time; and (4) reporting bias or bias towards reporting only significant results.

Of the articles identified by Duperrex et al. (2002) and Schwebel et al. (2014b), a few are noteworthy based on the quality of methods and findings. Downing et al. (1981) evaluate a road safety booklet using a sample of 15603 years old and their parents in the United Kingdom. The program randomly assigned the participants into four categories: (1) road safety booklet after an informative interview; (2) interview with no booklet; (3) road safety booklet with an informative letter; and (4) no intervention. The study found that the booklet had a significant impact on the children's traffic and road safety knowledge, but there appeared to be no change in mothers' road safety actions, which could be related to the difficulty in changing long-standing practices. These results highlight the difficulty that these programs might encounter in changing regular behaviors, particularly for older people. Also, there is no evidence of differential effects when comparing approaches that reach households through an interview compared to sending letters, which is relevant for cost-effectiveness. Finally, there are no heterogeneous effects across social class, but rural mothers seemed to make less use of the booklet than urban mothers, underscoring the importance of targeting when designing these programs.

Another relevant study by Miller and Davis (1982) evaluates training methods using multimedia technologies and explores both short- and medium-term outcomes. The authors analyze the Beltman Program, which was designed to increase knowledge about pedestrian safety and out-of-school safety behaviors among kindergarten and first- and second-grade students in the United States. The program included two intervention groups and one control group. The first intervention group received the Beltman materials, which included three filmstrips, numerous props, and teaching aids. The program gave two booster lessons to the second intervention group 4 months after they received the initial materials. Students' knowledge scores and observed out-of-school safety behaviors by parents were measured at baseline, after the test, and at a 5-month follow-up test. The authors found significant increases in knowledge in the two intervention groups at both the first post-test and the follow-up test, but the differences in knowledge scores between the two intervention groups were not significantly different at either post-test.

Traditional methods of teaching children road safety skills may be difficult to transfer to real-life situations. For this reason, more recent training programs have used simulated or virtual road environments. Experimental evidence indicates that children exposed to virtual reality training significantly improved their abilities to cross streets 
(Bart et al. 2008; Congiu et al. 2007), with the impact increasing by age. In some cases, findings show that positive effects are observed both immediately after training and 1 month after training, but that those effects could dissipate over time.

\subsubsection{Awareness campaigns}

Public awareness campaigns are another hallmark of road safety strategy, but there is very limited evidence on their effectiveness. As Hoekstra and Wegman (2011) indicate, ineffective campaign techniques continue to be utilized. From a policymaker's perspective, campaigns can be attractive tools given their wide scope or reach and potentially low cost. From the evaluation point of view, the level at which the campaign is offered influences the ability to rigorously evaluate it. To the extent that the campaign is targeted at certain populations or households and that the presence of spillover effects can be ruled out, evaluation becomes more feasible.

A meta-analysis by Elvik et al. (2009) showed that the effects of mass media campaigns alone are small, especially when compared to the effects of campaigns combined with other measures. Without enforcement and/or education, mass media campaigns were found to have virtually no impact on reducing the number of road accidents. However, enforcement and/or education coupled with mass media showed more promise, with reductions of over $10 \%$ in the number of accidents. Local or personally directed campaigns seem to have the biggest effect on road accidents, but there are a few studies looking at this type of campaign, which increases the uncertainty about the true value of this parameter. As Hoekstra and Wegman (2011) argue, insights into human behavior and behavior modification are important for road safety campaigns and are a promising area for future evaluation.

One of the first rigorous experiments of an awareness campaign in a developingcountry context was conducted by Habyarimana and Jack (2011), who examined a campaign aimed at improving the safety of long-distance minibuses (known as "matatus") in Kenya. In the study, stickers with evocative messages directed to passengers and encouraging them to "stand up, speak up, when they witnessed drivers who were going too fast or driving unsafely, were randomly assigned to just over half of 2276 recruited vehicles. To obtain high rates of compliance, the program ran a monthly lottery among drivers participating in the treatment group that offered monetary rewards if their vehicle was found to have all stickers intact upon inspection by field staff. Independent insurance claims that data were collected for treatment and control groups before and after the intervention. Results indicated that placing stickers in matatus was associated with a reduction in insurance claims by about half to two-thirds, from a baseline annual rate of about $10 \%$, and that claims involving injury or death fell by $60 \%$. While the authors were unable to identify the mechanisms underlying this effect, the intervention was more cost-effective at reducing mortality than other documented public health interventions.

\subsubsection{Laws to promote transportation safety}

This section reviews the effects of legislation to promote transport safety, specifically drinking and driving laws and motorcycle helmet laws. It is well established that driving under the effects of alcohol increases the chance of a road accident. Driving with blood alcohol content between 0.02 and $0.05 \mathrm{~g} / \mathrm{dl}$ triples the risk of a road accident. According to WHO (2015), the risk increases to at least six times with a blood alcohol content between 
0.05 and $0.08 \mathrm{~g} / \mathrm{dl}$ and rises exponentially above $0.08 \mathrm{~g} / \mathrm{dl}$. Albalate (2008) evaluates the impact of reducing the blood alcohol content limit to $0.5 \mathrm{mg} / \mathrm{ml}$ in several European countries over the last decade. The author uses the Community Database on Accidents on the Roads in Europe (CARE) for the period 1991-2003. Using a difference-in-differences method with fixed effects, the author shows that lowering the blood alcohol content limit to $0.5 \mathrm{mg} / \mathrm{ml}$ was an effective tool for saving lives in some road user groups, particularly males, drivers in urban areas, and all drivers between 18 and 49 years old.

A similar study in LAC examined Chile's 2012 law that lowered the permissible blood alcohol content threshold from 0.5 to $0.3 \mathrm{mg} / \mathrm{ml}$, and instituted severe financial and license revocation penalties for offending drivers. Rau and Otero (2017) show that alcohol-related car accidents decreased by $32 \%$ immediately following approval of the law, but that effects decrease over time. This was associated with a reduction in injuries; however, there were no significant effects on fatalities. In a second study using municipalitylevel administrative records, Otero (2013) employs a difference-in-differences strategy to estimate the causal impact of the law on car accidents and fatality rates. Given the quality of data on the cause of car accidents, the author uses all car accidents due to car or road technical failures as a comparison group. Results indicate that the law reduced the number of alcohol-related car accidents by $18 \%$ to a quarter of all accidents, which is entirely driven by non-fatal incidents. Evidence also indicates that the law works by increasing sober driving, not by reducing drunk drivers' alcohol consumption.

A second area of legal intervention to improve road safety is motorcycle helmet laws. Peng et al. (2017) review the literature in the United States and find that laws increased helmet use and reduced mortality and injuries for motorcyclists. However, several studies included in the review suffered from methodological limitations, such as not performing blinded assessment of outcomes, few data points, missing data, etc. A recent study by Blanco et al. (2017) in the Uruguayan context uses a "natural experiment" whereby a motorcycle helmet usage law was enforced in one municipality but not in another, and finds that within 1 month of the law's enforcement, usage of helmets increased from under $10 \%$ to over $90 \%$, and there was a reduction in the probability of serious injuries or fatalities by 8.7 percentage points (a $57 \%$ reduction relative to the control group).

\subsubsection{Incentive mechanisms to promote safe driving}

Road safety policies often use incentive mechanisms based on traffic violations to promote safe driving, such as fines, experience rating, and point-record driver's licenses. Dionne et al. (2011) propose a function of convicted traffic offenses and accidents with a proportional hazard model, and tested the model with data from the Quebec public insurance plan. The authors find evidence of moral hazard, where drivers who accumulate demerit points become more careful because they are at risk of losing their license. An insurance rating scheme introduced in 1992 reduced the frequency of traffic violations by 15\%. The authors use this result to derive monetary equivalents for traffic violations and license suspensions.

\subsection{Safer roads and mobility}

Road infrastructure is another factor that contributes to accidents. For this reason, beyond safety education programs and campaigns directed at changing risky behaviors, many road infrastructure projects are now introducing road safety components as 
part of their design. This section reviews the evidence from two different approaches. The first involves the adoption of engineering designs that are thought to provide safer roads, such as adjusting the shape of streets, the width of lanes, slopes, etc. The second group involves interventions such as adopting technology to promote road safety. These interventions include signaling, red lights in critical crossing sections of the road, and/or cameras to identify and penalize bad driving, among others.

\subsubsection{Infrastructure designs: converting intersections to roundabouts}

Elvik (2007) conducted a meta-analysis of projects implemented outside of the United States to evaluate the effects of converting intersections to roundabouts on road safety. The author provides 113 estimated effects derived from 28 studies. Among all the studies, only three used before-and-after techniques that included a control group. ${ }^{5}$ The remaining studies were based on before-and-after methods or comparative analysis of various types of intersections. None of the studies came from a developing country, and all pertained to either a European country or Australia. The main conclusions of the analysis were that roundabouts are associated with a $30-50 \%$ reduction in the number of injury accidents. Fatal accidents are reduced by 50 to $70 \%$. Evidence from the evaluation studies, although highly uncertain, suggests that the effect of roundabouts on injurious accidents is greater in four-leg intersections than in three-leg intersections, and it is greater in intersections previously controlled by yield signs than in intersections previously controlled by traffic signals. A few studies have evaluated the effects of design parameters for roundabouts. While findings from the studies are not always consistent, most find that small roundabouts (a small diameter of the central traffic island) are safer than large roundabouts (a large diameter of the central traffic island).

In general, roundabouts have a favorable effect on traffic safety, at least for crashes causing injuries. The number of severe crashes (fatalities and accidents involving serious injuries) appears to decrease after converting intersections into roundabouts. However, less is known about the safety effects of roundabouts for different types of road users, such as bicyclists. Daniels et al. (2008) conducted a before-and-after study with the use of a comparison group on a sample of 90 roundabouts in Flanders, Belgium to assess the effects of this intervention on bicyclists. The study revealed a significant increase in the number of severe injury crashes with bicyclists after the construction of a roundabout. Roundabouts with cycle lanes perform worse regarding injury crashes with bicyclists compared to three other design types (mixed traffic, separate cycle paths, and gradeseparated cycle paths). Roundabouts that replace signal-controlled intersections seem to have had a worse evolution compared to roundabouts on other types of intersections.

\subsubsection{Technology interventions: speed cameras}

Multiple road safety interventions make use of technology to reduce risky behaviors. One example is the use of cameras to reduce speed. Usually, cameras capture the license plate of passing vehicles exceeding a speed above the legal limit and mail a fine and penalty points to the driver of the vehicle. The main argument to install speed cameras is that by reducing speed, they contribute to preventing accidents.

${ }^{5}$ These studies are Giæver (1990), Jørgensen and Jørgensen (1992), and Brüde and Larsson (1985). Unfortunately, none of these studies are available in English. 
This type of intervention has been studied extensively, including by Christie et al. (2003), who analyzed the effectiveness of mobile speed cameras on road traffic injuries in South Wales in the United Kingdom. The authors study the use of mobile speed cameras at 101 sites to compare the rate of car accidents with a matched control group that was obtained from Gwent, a neighboring county with almost no speed cameras. ${ }^{6}$ The authors found that mobile speed cameras reduced personal injury accidents by $50 \%$ and pedestrian accidents by $78 \%$. One of the main limitations of the study is that it is assumed that cameras did not cause diversion of vehicles to other sites, which could explain the difference. Also, due to lack of data, the study was not able to control for other covariates that may have varied over time differently across treatment and control sites, such as traffic volume.

\subsubsection{Technology interventions: red-light cameras}

Many drivers routinely run red lights, placing themselves and other road users at risk for crashes and serious injuries (Retting et al. 2007). To reduce this problem, multiple countries have adopted red-light enforcement cameras. The technology usually consists of a camera that photographs the license plates of vehicles that enter an intersection after the signal has turned red. After a process of review and validation, an approved citation, along with the photograph of the violation, is sent to the registered owner of the vehicle (Garber et al. 2007). There is still no consensus on the effectiveness of red-light camera programs. Methodologies used to assess these programs have varied, as have the study conclusions. In general, the main criticism of the studies has been the use of simple methods (before-and-after comparisons) and small samples (Burkey and Obeng 2004).

Two principal methods used to reduce red-light running involve lengthening the duration of yellow signal intervals and automated red-light enforcement. Retting et al. (2007) evaluate the incremental effects on red-light running of first lengthening yellow signal timing, followed by the introduction of red-light cameras. They worked at two intersections in Philadelphia, Pennsylvania, where yellow change intervals were increased by about $1 \mathrm{~s}$, followed several months later by red-light camera enforcement. They included two comparison sites (approx. 50 miles apart) that authors argue were close enough to expect similar patterns in terms of weather, fuel prices, and economic conditions, and that collected violation data. The baseline recorded the number of red-light running violations, while the follow-ups included data several weeks after the implementation of the yellow timing changes, and about 1 year after the beginning of red-light camera enforcement. The authors estimated the odds of red-light running at the experimental sites relative to the comparison sites following implementation of yellow timing changes. Results showed that yellow timing changes reduced red-light violations by $36 \%$. The inclusion of red-light camera enforcement further reduced red-light violations by $96 \%$ beyond levels achieved by the longer yellow timing. This study shows that the provision of adequate yellow signal timing

\footnotetext{
${ }^{6}$ The unit of observation was determined by mapping the cameras, matched sites, and the crashes at both sites. The authors considered circular zones of different radius around the camera and matched site and a route-based method that defines exposure at various distances from sites. To determine the effectiveness of the mobile cameras, they computed the ratio of car accidents at the implemented and matched control sites before and after the intervention. For example, an intervention-control pair with six injurious crashes in the control-before and seven injurious crashes in the intervention-before period would have a matching ratio of 0.86 , and if there were four injurious crashes in the controlafter period, the expected number in the intervention-after period would be $4 / 0.86=4.7$.
} 
reduces red-light running, but longer yellow timing alone did not eliminate the need for better enforcement, which can be provided efficiently by red-light cameras.

Garber et al. (2007) studied the effectiveness of photo-red enforcement programs to address the problem of red-light running in Northern Virginia jurisdictions. A preliminary analysis in Fairfax County suggested that red-light running crashes decreased, but that rear-end crashes increased, after the cameras were installed. The authors' aim was to understand whether this result can be generalized to other counties and to quantify the net change in crash severity arising from this type of intervention. They used a data set including more than 3500 crashes over a 7-year period (1998-2004) at 28 intersections with cameras and 44 intersections without cameras. The authors use four methodologies ranging from simple before-after comparisons to an empirical Bayes approach. The authors defined crash severity as the total number of injury crashes and crash cost. ${ }^{7}$ The results varied depending on the type of crash, the jurisdiction, and the analytic technique used. The findings show that after cameras were installed, rear-end crashes increased by $27 \%$ and red-light running crashes decreased by $42 \%$, but the trends varied across counties. Overall, total crashes increased after the intervention, but there was a reduction in crash costs. Authors argue that measuring severity is very sensitive to assumptions.

A more recent impact evaluation also found positive results from red-light camera interventions. Hu et al. (2011) analyzed data on fatal crashes from 14 large U.S. cities with red-light camera enforcement programs and 48 cities without camera programs for 1992-1996 and 2004-2008. The average annual citywide rate of fatal red-light-running crashes declined around $14 \%$ for both groups, but the rate for cities with camera enforcement fell 35\%. During 2004-2008, the rate of fatal red-light-running crashes citywide and at signalized intersections were $24 \%$ and $17 \%$ lower, respectively, than what would be expected without cameras. By examining citywide crash rates for cities with camera programs and using similar control cities, the study accounted for two common weaknesses of red-light camera research: regression to the mean and spillover effect.

\subsection{Safer vehicles}

\subsubsection{Vehicle inspections and road safety}

As cars grow older, their technical condition deteriorates and their chances of being involved in an accident increase (Fosser 1992). Earlier studies offered inconclusive findings about the impact of vehicle inspections. For example, a study by Crain (1980) in the United Stated did not find an impact of vehicle inspections on car accident reduction, while a study by Matre and Overstree (1982), also in the United States, found that both random and non-random inspections were effective in reducing accident mortality. In both cases, the studies run regressions at the state level controlling for differences in vehicle inspection laws across states, and thus, they might not be accounting for all potential confounders. Some more recent studies introduce time-series analysis and report that periodic motor vehicle inspection is effective in preventing accidents. For instance, Sweden introduced mandatory annual inspection of all cars in 1966. According

\footnotetext{
7 Crash costs are calculated by the U.S. Federal Highway Administration. These costs include damage to vehicles and other property, costs from providing emergency medical services, medical costs, productivity losses, and "monetized quality-adjusted life years." Costs are based on the speed limit (either $45 \mathrm{mph}$ and above or below $45 \mathrm{mph}$ ), location type (e.g., signalized intersection), and crash type (rear-end or angle).
} 
to a time-series analysis conducted by Berg et al. (1984) covering 1955-1981, the authors concluded that the number of cars involved in police-reported accidents declined by $14 \%$ following the introduction of annual inspections, while the number of injurious accidents decreased by 15\%. Another time-series analysis covering 1929-1979 (Loeb and Gilad 1984) found that periodic motor vehicle inspections in New Jersey, introduced in 1938, reduced the number of fatalities and accidents. There are some uncertainties in time-series analyses, as several factors can be expected to affect the number of accidents during extended periods of time. Some studies have tried to consider some of these factors, like changes in the use of seatbelts, daytime running lights, and traffic volume. However, there may be time-changing observable and unobservable variables remaining that do not allow for isolating the effect of vehicle inspections.

Little (1971) performed a controlled before-and-after study using data from the United States to identify the effect of motor vehicle inspection on road accidents. The author designed a treatment group composed of six states and three control groups to test the null hypothesis that states that begin inspection programs experience no greater decline in death rates in post-treatment years than in pre-treatment years compared to states with no inspections. The results indicate that the fatality rate per 100,000 population increased following the introduction of periodic motor vehicle inspection. The use of control groups is an advantage of this study, but it does not rule out the effect of unobservable and observable (not controlled for) characteristics that change over time and affect treatment and control groups differently. For example, a high rate of economic growth in treatment states could lead to an increase in traffic volume and, subsequently, in the number of road accident fatalities.

The first experimental evaluation of the effects of periodic motor vehicle inspections on accident rates was conducted by the Norwegian Institute of Transport Economics (Fosser 1992). The study randomly assigned 204,000 cars to three different experimental conditions: 46,000 cars were inspected annually during a period of 3 years; 46,000 cars were inspected once for 3 years; and 112,000 cars were not inspected. The number of accidents was recorded for a period of 4 years. No differences in accident rates were found between the groups, although the technical condition of inspected vehicles improved compared to those not inspected.

\subsubsection{Fuel economy standards, vehicle size, and road safety}

An emerging literature has looked at how fuel economy standards that change the composition of the vehicle fleet toward smaller and lighter vehicles can potentially influence accident fatality risks. These studies shed some light on how regulatory safety standards in vehicle production could affect road safety. Jacobsen $(2011,2013)$ estimated the direction and magnitude of the U.S. fuel economy policy using structural models to provide empirical estimates of vehicle safety across classes, accounting for unobserved driving behavior and selection. ${ }^{8}$ Jacobsen (2011) showed that the distinction between light

\footnotetext{
${ }^{8}$ In general, impact evaluation relies on reduced-form approaches, where the primary interest is the direct relationship between a program or intervention and certain outcomes. Selection bias and the problem of unobserved counterfactuals are the primary identification issues for impact evaluators. In some cases, however, one may be interested in modeling other factors affecting policies and outcomes in a more comprehensive framework. Structural models or simultaneous equation models can help to create a schematic for interpreting policy effects from regressions, particularly when multiple factors are at work. These models specify interrelationships among endogenous variables (such as outcomes) and exogenous variables or factors (Khandker et al. 2010).
} 
trucks and cars in fuel economy rules has very negative consequences for overall safety: each mile per gallon increment is associated with an additional 150 fatalities per year in expectation. Jacobsen (2013), however, applied his model to the current structure of U.S. fuel economy standards, accounting for shifts in the composition of vehicle ownership, and estimated an adverse safety effect of 33 cents per gallon of gasoline saved.

Road safety can also be affected by vehicle size. This feature of road safety led Anderson (2008) to study the effects of size on traffic safety. The author estimated the net effect of vehicle fleet composition on traffic fatalities using a state-level panel data set. Moreover, with a random sample of police-reported accidents, he estimated the effects of light trucks on their own occupants and on other roadway users when an accident occurs. Finally, combining the results from the state-level and accident-level estimation strategies, he determined the relative crash rate of light trucks as compared to cars to estimate the total internal and external effects of shifting the vehicle fleet composition from cars towards light trucks. The results indicated that a $1 \%$ point increase in the light truck share raises annual traffic fatalities by $0.34 \%$, or 143 deaths per year. Of this increase, approximately one-fifth accrues to the light trucks' own occupants, and the remaining four-fifths accrue to the occupants of other vehicles and pedestrians. Using standard value-of-life figures, the implied Pigovian tax is approximately US $\$ 3850$ per light truck sold. Overall, light trucks pose a significant hazard to other users of the highway system, and, on average, provide no additional protection to their own occupants.

Similarly, Anderson and Auffhammer (2014) looked at the external costs of vehicle weight, particularly those related to fatal and non-fatal accidents. The authors' argument is that heavier vehicles are safer for their occupants but more hazardous for other vehicles. Therefore, any unregulated vehicle fleet should be inefficiently heavy. Using three separate identification strategies, they showed that, controlling for own-vehicle weight, being hit by a vehicle that is $1000 \mathrm{lb}$ heavier generates a $40-50 \%$ increase in fatality risk. These results imply a total accident-related externality that exceeds the estimated social cost of U.S. carbon emissions and is equivalent to a gas tax of $\$ 0.97$ per gallon (US\$136 billion annually). They considered two policies for internalizing this external cost-a weight-varying mileage tax, and a gas tax-and found that they are similar for most vehicles. Their findings suggest that European gas taxes may be much closer to the optimal levels than the United States gas tax.

\subsubsection{Vehicle recalls and road safety}

Another regulatory safety standard targeted at reducing road accidents is vehicle recall. For instance, in the United States, the number of automobile recalls has increased sharply in the last two decades, ${ }^{9}$ but there is still little quantitative evidence of this policy on safety. Bae and Benítez-Silva (2011) empirically quantified the impact of vehicle recalls on safety using repeated cross sections on accidents of individual drivers and aggregate vehicle recall data to construct synthetic panel data on individual drivers of a vehicle model. They found that a $10 \%$ increase in the recall rate of a specific model reduces the accidents of that model by 0.78 of a percent. They also concluded that recalls

${ }^{9}$ According to the Bureau of Transportation Statistics, 8,408,000 vehicles were recalled in 1993, while in 2011, the number of vehicles recalled was $15,500,000$ 
classified as "hazardous" are more effective in reducing accidents, and that vehicle models with recalls with higher correction rates have, on average, fewer accidents in the years following a recall, which indicates the importance of the role of drivers' behavior regarding recalls on safety. No similar studies were found for Latin America and the Caribbean.

\section{Conclusions}

Traffic deaths are one of the leading causes of death in LAC, and deaths and injuries from traffic accidents impose significant costs on the region. Available evidence (primarily from high-income countries such as the United States, United Kingdom, and Norway) suggests that effective policies can be implemented to improve road safety. However, evidence-based solutions need to be adapted and rigorously tested in the region. This paper takes a first step to laying the groundwork for a research agenda on road safety in LAC by summarizing existing theoretical literature and reviewing empirical evidence to date. Overall, the paper identified few rigorous impact evaluations on road safety. Most of the studies are observational, and among those that have tried to estimate causal effects, many suffered from small sample sizes and from selection of controls groups. Moreover, the literature has been concentrated in a few areas, such as road safety education, regulatory safety standards for vehicles, and institutional and normative frameworks.

Our review of the literature concentrates on three of the five pillars of road safety identified by the United Nations. The safer roads and mobility pillar highlights the importance of planning, designing, and constructing safe infrastructure. Roads in developing countries tend to be used by large numbers of motorcyclists, non-motorized vehicles, and pedestrians, and they lack safety features to protect these vulnerable populations, such as pedestrian crossing facilities, motorcycle lanes, and signs, among others (Global Road Safety Partnership 2016). The causal literature within this pillar is limited, probably due to the inherent methodological challenges in evaluating infrastructure interventions that are usually not randomly placed and, in many cases, are undertaken gradually in one or few locations. However, this review was able to identify some causal studies exploring the effects of modifying certain infrastructure designs (e.g., roundabouts) within urban areas. It also identified studies that examine other engineering solutions such as the incorporation of technologies (speed and red-light cameras) to promote safe behaviors.

The safer vehicles pillar seeks to encourage the purchase, operation, and maintenance of safer vehicles, ideally harmonizing global safety standards. Since 2010, crash tests on leading car brands sold across the region have revealed that many models were being sold without basic safety devices such as anti-lock braking systems and airbags, and had chassis that crumple far too easily on impact (Stocker 2012). This puts the driving population in the region at a higher risk of road accidents. This review presented studies that evaluate the impact of vehicle inspections, vehicle recalls, and fuel economy standards that result in lighter and smaller vehicles and which might have an impact on road safety.

The safer road users' pillar deals with enforcement and legislation, as well as with awareness campaigns and education programs. This is the area where the largest amount of evidence was identified, particularly for road safety education programs, including several randomized-controlled trials that have been implemented in high-income countries and that target children below 14 years old. Within this pillar, causal studies 
were also identified that explore the impact of awareness campaigns, drunk driving laws, motorcycle helmets, and other incentive mechanisms that seek to promote safe driving.

This exercise led to extracting some implications for future interventions, either led by public or private actors, and to highlighting areas of work that need more exploration within road safety evaluations. For road safety education, vulnerable populations such as the elderly and children are potential target groups. Education campaigns could consider testing individualized versus group training and technology-assisted versus non-technology methods, including education entertainment (films, videos, and booklets). Since knowledge does not necessarily translate into behavior, education-based interventions should focus on measuring behavioral outcomes.

For infrastructure strategies, it would be valuable to design impact evaluation studies that examine the impact of traffics signs on behavior in the LAC context, since studies to date are based primarily on simulations. There is a large scope for implementing experimental evaluations of technology to promote safe behaviors, including intelligent traffic lights, red-light cameras, speed cameras, and others. Finally, road maintenance could also play a role in road safety, so designing studies that examine multiple methods to achieve adequate road maintenance could be included in the agenda.

With respect to interventions targeted at vehicles, there is considerable evidence from studies of periodic vehicle inspections (one using an experimental design, but none of them in the region), and it would be valuable to understand better enforcement mechanisms for inspection in LAC. There is a dearth of evidence on car production and used car sales regulations, and much of the literature on the impact of vehicle size and road safety is based on structural models, which points to the need for more reduced-form evidence. Finally, within the institutional and normative framework, it is important to deepen understanding of drunk drinking and compulsory helmet laws as well as other legal and regulatory frameworks that may improve road safety.

From a methodological point of view, the gold standard in impact evaluation has been randomized-controlled trials, and the evaluation of road safety interventions offers multiple possibilities for experimentation. However, as Christie et al. (2003) explain, randomized-controlled trials have been difficult to implement in the field due to differences in beliefs between academics and some injury control practitioners and politicians that the existing evidence is sufficiently persuasive. It will be important to continue showcasing the value of building more rigorous causal evidence (Gertler et al. 2016) in this area, but also to consider that in certain circumstances, the evaluation will require the use of quasi-experimental designs, based on the characteristics of the intervention. Moreover, qualitative data are a valuable complement for causal evidence and allow for a more nuanced understanding of the mechanisms through which impacts happen. Given that several road safety interventions are implemented at an aggregate geographical level, such as campaigns in a city, or traffic signs along a highway, and to the extent that road safety data become more available with high frequency, methodologies such as synthetic control methods (Abadie and Gardeazabal 2003; Abadie et al. 2009) could open new avenues for evaluation. 


\section{Abbreviations}

GDP: Gross Domestic Product; LAC: Latin America and the Caribbean; UN: United Nations.

\section{Acknowledgements}

The opinions expressed in this publication are those of the authors and do not necessarily reflect the views of the Inter-American Development Bank Group, its respective Boards of Directors, or the countries which they represent. The authors would like to thank Dalve Alves for helpful comments on earlier versions of this paper

\section{Authors' contributions}

SM and PY-P conceived of and outlined the content of this paper. RS and PY-P conducted literature reviews, data analysis, and preparation of tables. SM, RS, and PY-P drafted and edited sections of the paper. All authors read and approved the final manuscript.

\section{Funding}

Generous funding for the elaboration of this paper and the book series was provided by the Inter-american Development Bank. All opinions are those of the authors and do not necessarily represent the views the Inter-American Development Bank Group, its respective Board of Directors, or the countries which they represent.

Availability of data and materials

All data used in this paper are available online.

\section{Competing interests}

The authors declare that they have no competing interests.

\section{Author details}

${ }^{1}$ Inter-American Development Bank, Washington D.C., USA. ${ }^{2}$ IDB Invest, Washington D.C., USA.

\section{Appendix}

See Tables 6, 7, and 8 .

Table 6 Projected top ten causes of death for 2030. (Source: Prepared by the authors based on data from WHO (2015))

\begin{tabular}{|c|c|c|c|c|c|c|c|c|}
\hline \multirow{3}{*}{$\begin{array}{c} \\
\\
\begin{array}{l}\text { Ischemic } \\
\text { heart } \\
\text { disease }\end{array}\end{array}$} & \multirow{3}{*}{$\begin{array}{l}\text { World } \\
9,245,111\end{array}$} & \multirow{3}{*}{$\begin{array}{l}\begin{array}{l}\text { High- } \\
\text { income } \\
\text { countries }\end{array} \\
1,393,090\end{array}$} & \multicolumn{6}{|c|}{ Low- and middle-income countries } \\
\hline & & & \multirow{2}{*}{$\begin{array}{l}\begin{array}{l}\text { East Asia } \\
\text { and Pacific }\end{array} \\
2,572,199\end{array}$} & \multirow{2}{*}{$\begin{array}{l}\begin{array}{l}\text { Europe } \\
\text { and Central } \\
\text { Asia }\end{array} \\
1,238,691\end{array}$} & \multirow{2}{*}{$\begin{array}{l}\text { Latin America } \\
\text { and Caribbean }\end{array}$} & \multirow{2}{*}{$\begin{array}{l}\begin{array}{l}\text { Middle East } \\
\text { and North } \\
\text { Africa }\end{array} \\
540,877\end{array}$} & \multirow{2}{*}{$\begin{array}{l}\begin{array}{l}\text { South } \\
\text { Asia }\end{array} \\
2,267,077\end{array}$} & \multirow{2}{*}{$\begin{array}{l}\begin{array}{l}\text { Sub- } \\
\text { Saharan } \\
\text { Africa }\end{array} \\
606,002\end{array}$} \\
\hline & & & & & & & & \\
\hline Stroke & $8,578,124$ & 866,778 & $3,637,130$ & 771,443 & 416,674 & 363,935 & $1,655,546$ & 866,618 \\
\hline $\begin{array}{l}\text { Chronic } \\
\text { obstruc- } \\
\text { tive pul- } \\
\text { monary } \\
\text { disease }\end{array}$ & $4,568,157$ & 445,821 & $1,507,041$ & 89,278 & 199,700 & 70,851 & $2,092,965$ & 162,501 \\
\hline $\begin{array}{l}\text { Lower res- } \\
\text { piratory } \\
\text { infections }\end{array}$ & $3,535,247$ & 524,961 & 601,006 & 63,162 & 282,238 & 103,462 & 727,734 & $1,232,684$ \\
\hline $\begin{array}{l}\text { Trachea, } \\
\text { bronchus, } \\
\text { lung } \\
\text { cancers }\end{array}$ & $2,413,401$ & 626,552 & $1,214,598$ & 148,078 & 117,401 & 41,767 & 220,041 & 44,965 \\
\hline $\begin{array}{l}\text { Other cir- } \\
\text { culatory } \\
\text { diseases }\end{array}$ & $1,929,188$ & 879,264 & 404,681 & 72,900 & 180,821 & 97,263 & 160,936 & 133,324 \\
\hline Road injury & $1,853,581$ & 72,024 & 391,304 & 38,075 & 131,289 & 118,637 & 588,620 & 513,632 \\
\hline HIV/AIDS & $1,793,500$ & 51,463 & 124,454 & 114,885 & 57,198 & 22,318 & 105,394 & $1,317,788$ \\
\hline $\begin{array}{l}\text { Diarrheal } \\
\text { diseases }\end{array}$ & $1,616,713$ & 54,202 & 70,331 & 6,912 & 20,418 & 15,226 & 859,824 & 589,800 \\
\hline $\begin{array}{l}\text { Hyperten- } \\
\text { sive heart } \\
\text { disease }\end{array}$ & $1,457,306$ & 251,561 & 412,501 & 87,247 & 163,892 & 90,298 & 292,174 & 159,632 \\
\hline
\end{tabular}


Table 7 Projected top ten causes of death among 15-29 years old for 2030. (Source: Prepared by the authors based on data from WHO (2015))

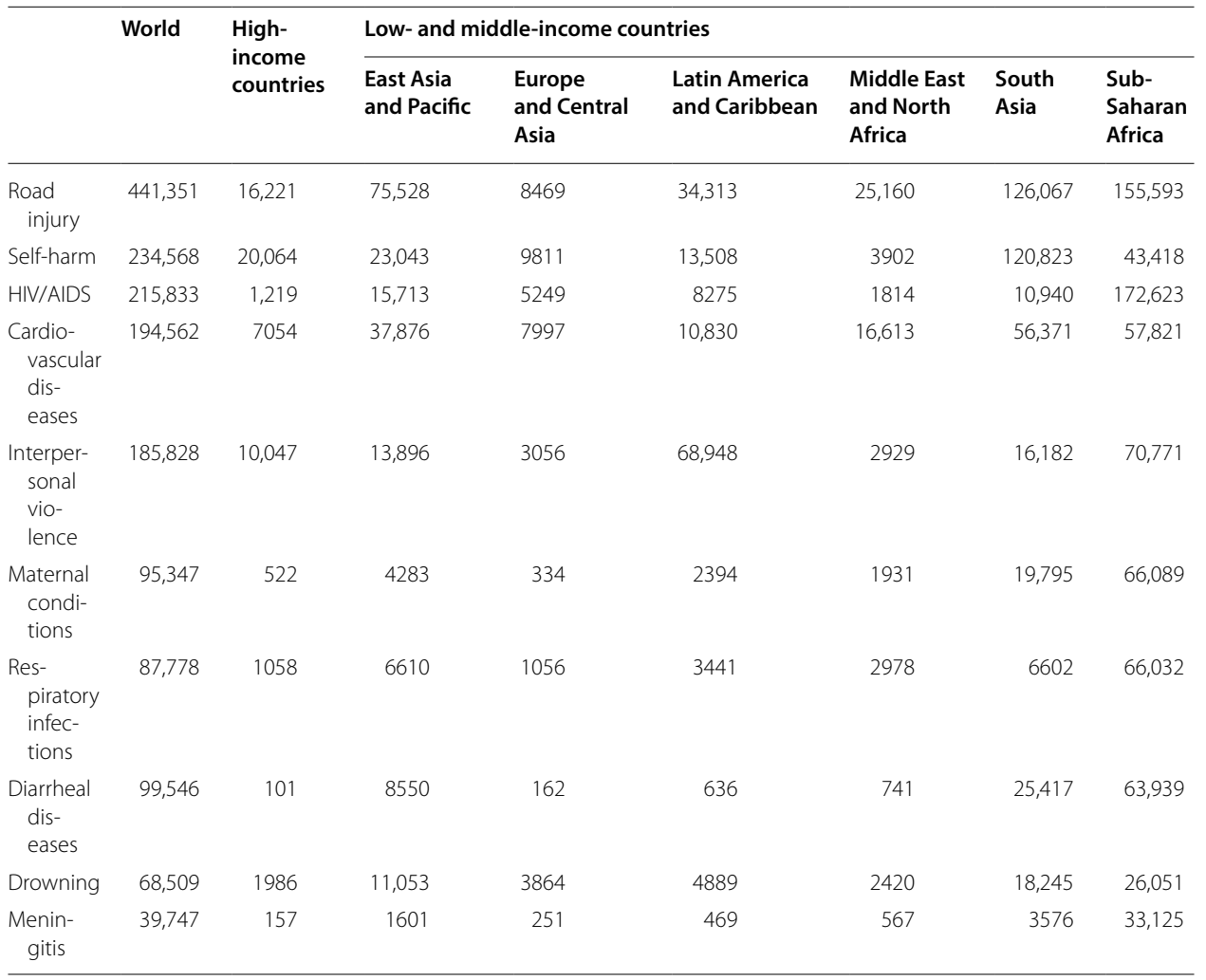

Table 8 National motorcycle helmet laws (percent). Source: Prepared by the authors based on data from WHO (2018)

\begin{tabular}{|c|c|c|c|c|c|}
\hline & $\begin{array}{l}\text { Existence } \\
\text { of a national } \\
\text { motorcycle } \\
\text { helmet law }\end{array}$ & $\begin{array}{l}\text { Requirement } \\
\text { for motorcycle } \\
\text { helmets } \\
\text { to meet } \\
\text { standards }\end{array}$ & $\begin{array}{l}\text { Requirement } \\
\text { for motorcycle } \\
\text { helmet to be } \\
\text { fastened }\end{array}$ & $\begin{array}{l}\text { Applicability } \\
\text { of national } \\
\text { motorcycle } \\
\text { helmet law } \\
\text { to all road } \\
\text { types }\end{array}$ & $\begin{array}{l}\text { Applicability } \\
\text { of national } \\
\text { motorcycle } \\
\text { helmet law to all } \\
\text { engine types }\end{array}$ \\
\hline $\begin{array}{l}\text { Andean South } \\
\text { Region }\end{array}$ & 100.00 & 60.00 & 50.00 & 100.00 & 100.00 \\
\hline Latin Caribbean & 100.00 & 50.00 & 50.00 & 100.00 & 100.00 \\
\hline Mesoamerica & 100.00 & 14.29 & 29.00 & 100.00 & 85.71 \\
\hline $\begin{array}{l}\text { Non-Latin Carib- } \\
\text { bean }\end{array}$ & 100.00 & 83.33 & 33.33 & 100.00 & 100.00 \\
\hline Southern Cone & 100.00 & 100.00 & 80.00 & 100.00 & 100.00 \\
\hline
\end{tabular}

Received: 28 August 2019 Accepted: 30 October 2019

Published online: 18 November 2019

References

Abadie A, Gardeazabal J (2003) The economic costs of conflict: a case study of the Basque country. Am Econ Rev 93(1):113-132

Abadie A, Diamond A, Hainmueller J (2009) Synthetic control methods for comparative case studies: estimating the effect of California's Tobacco Control Program. J Am Stat Assoc 105:493-505 
Albalate D (2008) Lowering blood alcohol content levels to save lives: the European experience. J Policy Anal Manag 27(1):20-39

Anderson M (2008) Safety for whom? The effects of light trucks on traffic fatalities. J Health Econ 27(4):973-989

Anderson M, Auffhammer M (2014) Pounds that kill: the external costs of vehicle weight. Rev Econ Stud 81(2):535-571 Bae Y, Benítez-Silva H (2011) Do vehicle recalls reduce the number of accidents? The case of the US car market. J Policy Anal Manag 30(4):821-862

Bart O, Katz N, Weiss P, Josman N (2008) Street crossing by typically developed children in real and virtual environments. Occup Particip Health 28(2):89-96

Berg G, Danielsson S, Junghard O (1984) Trafiksakerhet och periodisk Fordonskontroll. VTI-Rapport 281. Statens Vag-och Trafikinstitut, Linkoping

Bhalla K, Diez-Roux E, Taddia AP, De la Peña Mendoza SM, Pereyra A (2013) The costs of road injuries in Latin America. Technical Note No IDB-TN-597. Inter-American Development Bank, Washington, DC

Blanco M, Cabrera JM, Carozzi F, Cid A (2017) Effects of motorcycle helmet laws on prevention of fatalities: an impact evaluation. Department of Economics Working Paper Series, Universidad de Montevideo

Blomquist G (1986) A utility maximization model of driver traffic safety behavior. Accid Anal Prev 18(5):371-375

Brüde U, Larsson J (1985) Korsningsåtgärder vidtagna inom vägförvaltningarnas trafiksäkerhetsarbete. Regressions-och åtgärdseffekter

Burkey M, Obeng K (2004) A detailed investigation of crash risk reduction resulting from red light. Munich Personal RePEc Archive Paper No. 36261

Christie S, Lyons R, Dunstan F, Jones S (2003) Are mobile speed cameras effective? A controlled before and after study. Injury Prev 9(4):302-306

Congiu M, Whelan M, Oxley J, D'Elia A, Charlton J, Fildes B (2007) Crossing roads safely: the effects of training on improving children's road crossing decisions. In: Paper presented at the Australasian Road Safety Research Policing Education Conference, Melbourne, Victoria, Australia

Crain W (1980) Vehicle safety inspection systems. How effective? American Enterprise Institute for Public Policy Research, Washington, DC

Crandall R, Graham J (1984) Automobile safety regulation and offsetting behavior: some new empirical estimates. Am Econ Rev 74(2):328-331

Daniels S, Brijs T, Nuyts E, Wets G (2008) Roundabouts and safety for bicyclist: empirical results and influence of different cycle facility designs. In: Paper presented at the National Roundabout Conference, Kansas City, Missouri

Diez-Roux E, Taddia A, De la Peña Mendoza S, Deza de la Vega C (2012) Closing the gap: reducing road traffic deaths in Latin America and the Caribbean-action Plan 2010-2015. Inter-American Development Bank, Washington, DC

Dionne G, Pinquet J, Maurice M, Vanasse C (2011) Incentive mechanisms for safe driving: a comparative analysis with dynamic data. Rev Econ Stat 93(1):218-227

Downing C, Murray G, Durow C (1981) Trials of a road safety booklet for a pre-school traffic club. Monograph No LR 992, Planning and Transport Res and Computation Co Ltd

Dulisse B (1997) Methodological issues in testing the hypothesis of risk compensation. Accid Anal Prev 29(3):285-292

Duperrex O, Bunn F, Roberts I (2002) Safety education for pedestrian for injury prevention: a systematic review of randomized controlled trials. BMJ 324(7346):1129-1134

ECLAC (2015) Latin America and the Caribbean maintains a high traffic accident mortality rate. Press Release, 11 November. Economic Commission for Latin America and the Caribbean. https://www.cepal.org/en/comunicados/ameri ca-latina-caribe-mantiene-alta-tasa-mortalidad-siniestros-transito. Accessed 2 Aug 2018

Elvik R (2002) The importance of confounding in observational before-and-after studies of road safety measures. Accid Anal Prev 34:631-635

Elvik R (2004) To what extent can theory account for the findings of road safety evaluation studies? Accid Anal Prev 36(5):841-849

Elvik R (2007) Effects on road safety of converting intersections to roundabouts: review of evidence from non-U.S. studies. Transp Res Rec J Transp Res Board 1847:1-10

Elvik R (2010) A restatement of the case for speed limits. Transp Policy 17(3):196-204

Elvik R, Vaa T, Erke A, Sorensen M (2009) The handbook of road safety measures. Emerald Group Publishing, Bingley

Farmer E, Chambers EG (1940) A study of accident proneness among motor drivers. Rev Stat Econ Books 103(2):254-256

Fosser S (1992) An experimental evaluation of the effects of periodic motor vehicle inspection on accident rates. Accid Anal Prev 24(6):599-612

Froggatt P, Smiley JA (1964) The concept of accident proneness: a review. Br J Ind Med 21(1):1-12

Fuller R (2005) Towards a general theory of driver behaviour. Accid Anal Prev 37(3):461-472

Fuller R, Santos I (2002) Psychology and the highway engineer. In: Fuller R, Santos J (eds) Human factors for highway engineers. Pergamon, Amsterdam

Garber N, Abel R, Miller J, Eslambolchi S, Korukonda S (2007) The impact of red-light cameras (photo-red enforcement) on crashes in Virginia. Document No. FHWANTRC 07-R2. Virginia Transportation Research Council and U.S. Department of Transportation Federal Highway Administration

Gertler P, Martinez S, Premand P, Rawlings L, Vermeersch C (2016) Impact evaluation in practice, 2nd edn. World Bank, Washington, DC

Giæver T (1990) Ulykkesfrekvenser i rundkjøringer og signalregulerte kryss. STF63 A90002

Global Road Safety Partnership (2016) Road Map Strategic Plan 2016-2020. International Federation of Red Cross and Red Crescent Societies. https://www.grsproadsafety.org/wp-content/uploads/2016/11/GRSP-Road-Map_StrategicPlan-2016-2020.pdf. Accessed 2 Aug 2018

Habyarimana J, Jack W (2011) Heckle and chide: results of a randomized road safety intervention in Kenya. J Public Econ 95:1438-1446

Hauer E (1997) Observational before-after studies in road safety: estimating the effect of highway and traffic engineering measures on road safety. Pergamon Press, Oxford 
Hoekstra T, Wegman F (2011) Improving the effectiveness of road safety campaigns: current and new practices. IATSS Res 34(2):80-86

Hu W, McCartt A, Teoh E (2011) Effects of red-light camera enforcement on fatal crashes in large US cities. J Saf Res 42(4):277-282

Jacobsen M (2011) Fuel economy, car class mix, and safety. Am Econ Rev 101(3):105-109

Jacobsen M (2013) Fuel economy and safety: the influences of vehicle class and driver behavior. Am Econ J Appl Econ 5(3):1-26 Janssen W, Tenkink E (1988) Considerations on speed selection and risk homeostasis in driving. Accid Anal Prev 20(2):137-142

Jørgensen E, Jørgensen N (1992) Er der mere nyt om rundkørsler? Dansk Vejtidsskrift 12:29-31

Khandker S, Koolwal G, Samad H (2010) Handbook on impact evaluation: quantitative methods and practices. World Bank, Washington, DC

Little J (1971) Uncertainties in evaluating periodic motor vehicle inspection by death rates. Accid Anal Prev 2(4):301-313

Loeb P, Gilad B (1984) The efficacy and cost-effectiveness of vehicle inspection: a state specific analysis using time series data. J Transport Econ Policy 18(2):145-164

Michon J (1989) Explanatory pitfalls and rule-based driver models. Accid Anal Prev 21(4):341-353

Miller D, Davis L (1982) Research report—Evaluation of Beltman traffic safety program for children. J Traffic Saf Educ 30(1):13-14

Näätänen R, Summala H (1974) A model for the role of motivational factors in drivers' decision-making. Accid Anal Prev 6(3):243-261

National Center for Injury Prevention and Control (2013) Web-based injury statistics query and reporting system. http:// www.cdc.gov/ncipc/wiqars

Noland R (2013) From theory to practice in road safety policy: understanding risk versus mobility. Res Transp Econ 43(1):71-84

O'Neill B (1977) A decision-theory model of danger compensation. Accid Anal Prev 9(3):157-165

Otero S (2013) Short-term effects of zero tolerance laws on drinking and driving in Chile. Pontifica Universidad Catolica de Chile. Dissertation

Peden M, Scurfield R, Sleet D, Mohan D, Hyder AA, Jarawan E, Mathers C (eds) (2004) World report on road traffic injury prevention. World Health Organization, Geneva

Peltzman S (1975) The effects of automobile safety regulation. J Political Econ 83(4):677-725

Peng Y, Vaidya N, Finne R, Reynolds J, Dumitru C, Njie G, Sleet DA (2017) Universal motorcycle helmet laws to reduce injuries: a community guide systematic review. Am J Prev Med 52(6):820-832

Rau T, Otero S (2017) The effects of drinking and driving laws on car crashes, injuries and deaths: evidence from Chile. Accid Anal Prev 106:262-274

Reason J (1990) Human error. Cambridge University Press, Cambridge

Retting R, Ferguson S, Farmer C (2007) Reducing red light running through longer yellow signal timing and red-light camera enforcement: results of a field investigation. Insurance Institute for Highway Safety

Rothengatter T (1988) Risk and the absence of pleasure: a motivational approach to modelling road user behaviour. Ergonomics 31(4):599-607

Schwebel D, McClure L, Severson J (2014a) Teaching children to cross streets safely: a randomized, controlled trial. Health Psychol 33(7):628-638

Schwebel D, Barton BK, Shen J, Wells HL, Bogar A, Heath G, McCullogh D (2014b) Systematic review and meta-analysis of behavioral interventions to improve child pedestrian safety. J Pediatr Psychol 39(8):826-845

Stocker E (2012) Latin America's traffic turning deadlier as shoddy cars clog bad roads. The Guardian. 2012. https://www. theguardian.com/global-development/2012/jul/24/latin-america-traffic-cars-roads. Accessed 2 Aug 2018

Struik M, Alexander K, Cave T, Fleming A, Lyttle J, Stone A (1988) Pedestrian accident project report no 4: Literature review of factors contributing to pedestrian accidents. Road Traffic Authority, Hawthorn, Australia

Summala H (1988) Risk control is not risk adjustment: the zero-risk theory of driver behaviour and its implications. Ergonomics 31(4):491-506

Taylor D (1964) Drivers' galvanic skin response and the risk of accident. Ergonomics 7(4):439-451

Thomson J (2005) Child pedestrian accidents: what makes children vulnerable? In: Gillham B, Thompson J (eds) Child safety: problem and prevention from pre-school to adolescence. Routledge, London

Tillmann W, Hobbs G (1949) The accident-prone automobile driver: a study of the psychiatric and social background. Am J Psychiatry 106(5):321-331

Van Matre J, Overstree G Jr (1982) Motor vehicle inspection and accident mortality: a reexamination. J Risk Insurance 49(3):423-435

Wijnen W, Stipdonk H (2016) Social costs of road crashes: an international analysis. Accid Anal Prev 94:97-106

Wilde G (1982) The theory of risk homeostasis: implications for safety and health. Risk Anal 2(4):209-225

Wilde G, Robertson L, Pless I (2002) Does risk homoeostasis theory have implications for road safety? BMJ 324(7346):1149-1152

World Bank (2017) The high toll of traffic injuries: unacceptable and preventable. World Bank, Washington

World Health Organization (WHO) (2010). Global plan for the decade of action for road safety 2011-2020. World Health Organization. http://www.who.int/roadsafety/decade_of_action/plan/en/. Accessed 2 Aug 2018

World Health Organization (WHO) (2013) Strengthening road safety legislation: a practice and resource manual for countries. World Health Organization, Geneva

World Health Organization (WHO) (2015) Global status report on road safety 2013: supporting a decade of action. World Health Organization, Geneva

World Health Organization (WHO) (2018) Road traffic injuries. https://www.who.int/news-room/fact-sheets/detail/roadtraffic-injuries. Accessed 22 Aug 2019

\section{Publisher's Note}

Springer Nature remains neutral with regard to jurisdictional claims in published maps and institutional affiliations. 